\title{
Presymptomatic diagnosis of von Hippel-Lindau disease with flanking DNA markers
}

\author{
E R Maher, E Bentley, S J Payne, F Latif, F M Richards, M Chiano, S Hosoe, \\ J R W Yates, $M$ L Linehan, D E Barton, G Glenn, N A Affara, M Lerman, B Zbar, \\ M A Ferguson-Smith
}

the short arm of chromosome 3 by Seizinger $e t$ $a l$ and subsequently we and others have localised the VHL locus telomeric to the RAF1 oncogene at 3p25-26 and have identified flanking markers..$^{8-10}$ This work offered the opportunity to develop presymptomatic diagnosis of VHL disease using linked DNA markers. However, before introducing this into clinical practice, we wanted to establish (1) reliable estimates of the position of the VHL disease locus with respect to widely available DNA markers, (2) accurate estimates of sex specific recombination fractions, (3) that there is no evidence of locus heterogeneity, and (4) the informativeness of currently available DNA markers for presymptomatic diagnosis. We investigated points (1) to (3) by reanalysing two previously published genetic linkage studies on 46 families with VHL disease, and then went on to study the suitability of currently available DNA markers for presymptomatic diagnosis in a further 14 families containing 23 asymptomatic relatives at $50 \%$ prior risk for VHL disease.

Cambridge University
Department of
Pathology,
Cambridge.
E R Maher
E Bentley
F M Richards
M Chiano
J R W Yates
N A Affara
M A Ferguson-Smith

Molecular Diagnostic Laboratory, East Anglian Regional Genetics Service, Cambridge. $S$ J Payne D E Barton

Laboratory of
Immunobiology,
National Cancer
Institute-Frederick
Cancer Research
Facility, Frederick,
USA.
F Latif
S Hosoe
G Glenn
M Lerman
B Zbar

B Zbar

Surgery Branch, National Cancer Institute, USA. $M$ Linehan

Correspondence to Dr Maher, Department of Clinical Genetics, Addenbrooke's Hospital, Hills Road, Cambridge CB2 2QQ.

Received 7 April 1992. Revised version accepted 27 May 1992. mates of sex specific recombination idence of locus heterogeneity. second part of this study, 14 families taining 23 asymptomatic subjects at $50 \%$ prior risk of VHL disease were investigated with closely linked DNA markers (RAF1, D3S18, D3S732). Seventeen subjects were informative with one or more markers, six of whom were informative at markers flanking the VHL disease gene. By combining age related and DNA based risk information the carrier risk for 11 subjects was reduced to $<2 \%$. (F Med Genet 1992;29:902-5)

Von Hippel-Lindau (VHL) disease is an autosomal dominant inherited disorder predisposing to a variety of benign and malignant tumours. The most frequent complications are haemangioblastomas of the central nervous system and retina, renal cell carcinoma, and phaeochromocytoma. ${ }^{1-3}$ The minimum birth incidence of VHL disease is $1 / 36000 .^{4}$ Penetrance is age dependent and is almost complete by 65 years of age. Mean age at diagnosis is 26.3 years. Patients with VHL disease often develop multiple tumours and the mean age of cerebellar haemangioblastoma and renal cell carcinoma in VHL disease patients is significantly younger than in sporadic cases. ${ }^{5}$ Median actuarial life expectancy is reduced to 49 years and renal cell carcinoma is the most common cause of death in VHL disease. ${ }^{3}$ Although the morbidity and mortality of VHL disease can be reduced by regular ophthalmological and systemic screening and the early diagnosis of asymptomatic complications, ${ }^{6}$ long term compliance with the complicated screening protocol may be difficult to achieve.

The gene for VHL disease was mapped to

\section{Methods}

COMBINED GENETIC LINKAGE ANALYSIS

The linkage data reported in two previous studies $^{89}$ was updated and reanalysed. The combined data set contained results for four loci (THRB, RAF1,D3S18, and D3S191) at chromosome 3 p24-p26 for 46 families (212 affected subjects, 339 unaffected relatives and spouses typed). Detailed information on experimental methods and clinical details are given in the original papers. Genetic linkage analysis with LIPED and LINKAGE programs was performed as described previously, ${ }^{9}$ except that new age dependent penetrance data were used for all families, and sex specific recombination fractions were calculated for the two point lod scores. The new penetrance figures were taken from the results of segregation analysis ${ }^{4}$ and are shown in table 1. A multipoint linkage map was constructed using the LINKMAP program. The background map and distances between marker loci were taken from Hosoe et al $l^{8}: R A F 1-0 \cdot 04-D 3 S 18$ $0.05-D 3 S 191$. Formal heterogeneity testing was performed with the HOMOG program.

PRESYMPTOMATIC DIAGNOSIS OF VHL DISEASE WITH LINKED DNA MARKERS

Patients

A further 14 families not included in the com- 
Table 1 Age dependent

penetrance classes for $V H L$ disease (from Maher et $\mathrm{al}^{4}$ ).

\begin{tabular}{cc}
\hline Age & Penetrance \\
\hline 5 & 0.01 \\
10 & 0.08 \\
15 & 0.19 \\
20 & 0.37 \\
25 & 0.52 \\
30 & 0.67 \\
35 & 0.78 \\
40 & 0.86 \\
45 & 0.91 \\
50 & 0.94 \\
55 & 0.96 \\
60 & 0.98 \\
\hline
\end{tabular}

bined linkage study were investigated in Cambridge to determine the usefulness of currently available DNA markers for presymptomatic diagnosis. These 14 families contained 23 asymptomatic subjects (mean age 23.3 years, range 10 to 45 years) at $50 \%$ prior risk for VHL disease (that is, each had an affected parent) and were studied with DNA markers flanking the VHL locus (see below). Each family was potentially informative for DNA analysis in that DNA was available from at least one parent and an affected sib.

\section{DNA markers}

DNA was extracted from peripheral blood samples, digested with the appropriate restriction enzymes, and analysed by electrophoresis and Southern blotting as previously described. ${ }^{9}$ Restriction fragment length polymorphisms were studied at $R A F 1, D 3 S 732$, and D3S18 (table 2). D3S191 was not used because it was only minimally informative in the families studied by Maher et al. ${ }^{9}$ The D3S732 locus has recently been identified and maps very close to $R A F 1 .{ }^{12}$ Genetic linkage studies in the $60 \mathrm{CEPH}$ reference pedigrees have not identified any recombinants between $R A F 1$ and D3S732 (maximum lod score $22 \cdot 7, \mathrm{~K}$ Tory, personal communication). For the risk calculations it was assumed that

Table 2 Details of restriction fragment length polymorphisms used for the presymptomatic diagnosis of VHL disease.

\begin{tabular}{|c|c|c|c|c|c|c|}
\hline Locus & Probe & $\begin{array}{l}\text { Restriction } \\
\text { enzyme }\end{array}$ & $\begin{array}{l}\text { Allele sizes } \\
\quad(\mathrm{kb})\end{array}$ & $\begin{array}{c}\text { Allele } \\
\text { frequency }\end{array}$ & $\begin{array}{c}\text { Frequency of } \\
\text { hetero- } \\
\text { zygosity }\end{array}$ & Ref \\
\hline $\begin{array}{l}R A F 1 \\
R A F 1 \\
D 3 S 732\end{array}$ & $\begin{array}{c}\text { p627 } \\
\text { p627 } \\
\text { LIB 4A- } \\
52^{\prime \prime}\end{array}$ & $\begin{array}{c}\text { TaqI } \\
\text { BglI } \\
\text { HindIII }\end{array}$ & $\begin{array}{c}6 \cdot 8,6 \cdot 3 \\
4 \cdot 0,3 \cdot 3 \\
9 \cdot 0 \\
7 \cdot 5+1 \cdot 5\end{array}$ & $\begin{array}{l}0.74,0.26 \\
0.54,0.46 \\
0.65,0.35\end{array}$ & $\begin{array}{l}0.34 \\
0.49 \\
0.46\end{array}$ & $\begin{array}{c}11,12 \\
11,12 \\
11\end{array}$ \\
\hline $\begin{array}{l}\text { D3S } 18 \\
\text { D3S18 }\end{array}$ & $\begin{array}{l}\text { c-LIB-I } \\
\text { CRI- } \\
\text { L162 }\end{array}$ & $\underset{\text { DraI }}{\text { BamHI }}$ & $\begin{array}{l}8 \cdot 7,4 \cdot 7 \\
3 \cdot 8,1 \cdot 5 \\
2 \cdot 8,1 \cdot 5\end{array}$ & $\begin{array}{c}0.69,0.31 \\
0 \cdot 3,0 \cdot 7 \\
0 \cdot 2,0.8\end{array}$ & $\begin{array}{l}0.43 \\
0 \cdot 38 \\
0 \cdot 17\end{array}$ & $\begin{array}{l}8 \\
8\end{array}$ \\
\hline
\end{tabular}

Table 3 Combined linkage analysis of 46 families with VHL disease: pairwise lod scores for linkage between VHL disease and chromosome 3 markers.

\begin{tabular}{lrrrrrrr}
\hline Locus & \multicolumn{7}{c}{ Recombination fraction } \\
\cline { 2 - 8 } & 0.00 & 0.01 & \multicolumn{1}{c}{0.05} & 0.10 & \multicolumn{1}{c}{0.20} & \multicolumn{1}{c}{0.30} & 0.40 \\
\hline THRB & $-\infty$ & -12.20 & -2.43 & 0.98 & 2.73 & 2.19 & 0.90 \\
RAF1 & $-\infty$ & 17.42 & 19.92 & 18.91 & 14.44 & 8.84 & 3.41 \\
D3S18 & $-\infty$ & 30.95 & 29.79 & 26.88 & 19.81 & 12.09 & 4.72 \\
D3S191 & $-\infty$ & 5.44 & 8.60 & 8.91 & 7.37 & 4.81 & 1.97 \\
\hline
\end{tabular}

$(R A F 1, D 3 S 732)$ and $D 3 S 18$ flank the VHL disease gene.

Risk analysis

A RFLP based carrier risk for informative at risk relatives was calculated by MLINK. The following recombination fractions were used for risk estimation (see Results): for VHL disease and $R A F 1$ : male specific 0.04 , female specific 0.07 ; for VHL disease and $D 3 S 18$ : male specific 0.01 , female 0.03 . The $D 3 S 732$ locus maps very close to $R A F 1^{12}$ so that the same recombination fractions were used for both. The age dependent penetrance classes shown in table 1 were used to calculate age related risks for each subject by standard Bayesian methods. A final carrier risk was derived by a Bayesian calculation combining the age related and RFLP based risks.

\section{Results}

COMBINED GENETIC LINKAGE ANALYSIS

Significant lod scores were obtained between VHL disease and $R A F 1, D 3 S 18$, and D3S191 (table 3). Sex specific recombination fractions are shown in table 4 . The female recombination fractions were significantly greater than the male at $R A F 1 \quad\left(\chi^{2}=5.66, \mathrm{p}<0.02\right)$ and D3S18 $\left(\chi^{2}=7 \cdot 13, \mathrm{p}<0.01\right)$. Multipoint linkage analysis confirmed that the VHL locus mapped to the RAF1-D3S18 interval (figure). The probability of the VHL gene mapping between $R A F 1$ and $D 3 S 18$ was 962 times greater than that of the next most likely location in the D3S18-D3S191 interval, and $32.96 \times 10^{6}$ more likely than a localisation centromeric to $R A F 1$.

Homogeneity testing with the HOMOG program provided no evidence for locus heterogeneity. The most likely proportion of linked families (alpha) was 1.0 (95\% confidence interval 0.85 to 1.0 ).

PRESYMPTOMATIC DIAGNOSIS OF VHL DISEASE Of the 23 asymptomatic relatives at $50 \%$ prior risk of VHL disease, 17 were informative at one or more loci, and six were informative at loci flanking the VHL disease gene. The proportion of informative patients was $33 \%$ at $R A F 1,46 \%$ at $D 3 S 732$, and $61 \%$ at $D 3 S 18$. Two asymptomatic subjects were predicted to be at high risk of developing VHL disease: one woman aged 22 years (DNA risk 98\%) was found to have a small asymptomatic cerebellar haemangioblastoma on an MRI brain scan and has subsequently developed symptomatic spinal haemangioblastomas. The other subject predicted to be at high risk (DNA risk $99 \%$ ) is aged 13 years and has not yet manifested any evidence of VHL disease. One at risk relative showed a recombination between informative flanking markers, so that it was not possible to determine his risk accurately. Fourteen subjects were predicted to be at low risk. The age related risk, RFLP based carrier risk, and combined risk for each subject are shown in table 5. Combined DNA and age related risks 
were less than $2 \%$ in 11 patients. All the 14 patients predicted to be at low risk of VHL disease remain asymptomatic and no manifestations of VHL disease have been detected on ophthalmological and systemic screening.

\section{Discussion}

The combined analysis of 46 families with VHL disease has provided more accurate estimates of the recombination fractions between the VHL locus and closely linked markers than can be derived from individual studies. Analysis of the combined data confirmed the localisation of the VHL disease gene to the RAF1-

Table 4 Combined linkage analysis of 46 families with VHL disease: peak lod scores and corresponding sex combined and sex specific recombination fractions.

\begin{tabular}{lcccc}
\hline Locus & Maximum & \multicolumn{3}{c}{ Recombination fraction } \\
\cline { 3 - 5 } & lod score & $\begin{array}{c}\text { Sexes combined } \\
\text { (confidence interval) }\end{array}$ & $\begin{array}{c}\text { Male } \\
\text { specific }\end{array}$ & $\begin{array}{c}\text { Female } \\
\text { specific }\end{array}$ \\
\hline THRB & 2.74 & $0.21(-)$ & - & - \\
$R A F 1$ & 19.92 & $0.05(0.02-0.10)$ & 0.04 & 0.07 \\
$D 3 S 18$ & 31.00 & $0.02(0.002-0.045)$ & 0.001 & 0.03 \\
D3S191 & 8.95 & $0.09(0.03-0.17)$ & 0.06 & 0.09 \\
\hline
\end{tabular}

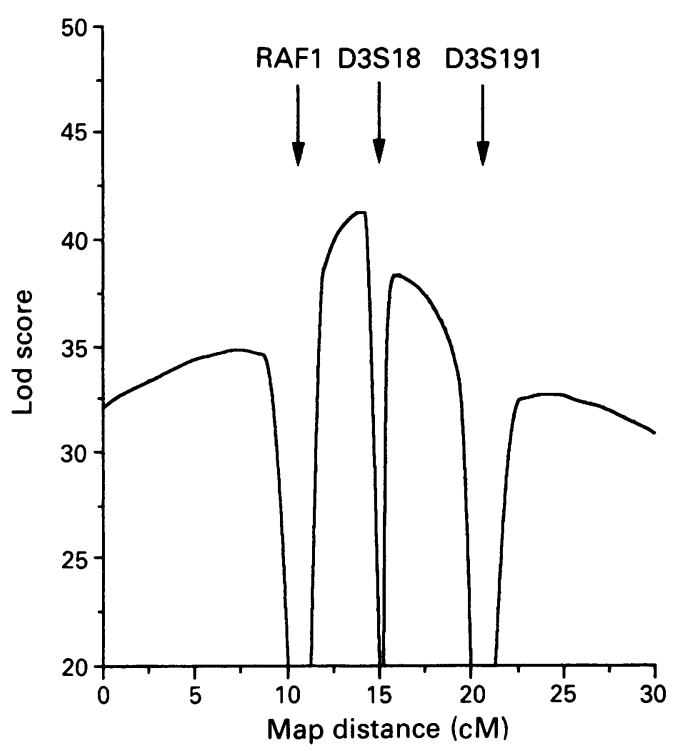

Multipoint genetic linkage analysis of 46 families with VHL disease. The most likely location of the VHL disease gene is between RAF1 and D3S18.

Table 5 Presymptomatic diagnosis of VHL disease using linked DNA markers: summary of 14 cases predicted to be at low risk. Age related risks were derived by a Bayesian calculation using the age dependent penetrance figures in table 1.

\begin{tabular}{|c|c|c|c|c|c|c|}
\hline \multirow[t]{2}{*}{ Family } & \multirow[t]{2}{*}{ Subject } & \multirow[t]{2}{*}{ Age } & \multirow[t]{2}{*}{ Informative loci } & \multicolumn{3}{|c|}{ Carrier risk } \\
\hline & & & & $\underset{(\%)}{\text { Age }} \begin{array}{c}\text { related } \\
(\%)\end{array}$ & $\begin{array}{c}\text { DNA } \\
\text { based } \\
(\%)\end{array}$ & $\begin{array}{c}\text { Combined age } \\
\text { related and DNA } \\
\text { based risk } \\
(\%)\end{array}$ \\
\hline $\begin{array}{l}\text { B } \\
\text { C } \\
\text { D }\end{array}$ & $\begin{array}{l}\text { III } \cdot 3 \\
\text { III } \cdot 1 \\
\text { II } 2 \\
\text { II } \cdot 3\end{array}$ & $\begin{array}{l}25 \\
40 \\
28 \\
23\end{array}$ & $\begin{array}{l}D 3 S 732, D 3 S 18 \\
R A F 1 \\
D 3 S 732, D 3 S 18 \\
R A F 1, D 3 S 732, \\
D 3 S 18\end{array}$ & $\begin{array}{l}32 \\
12 \\
27 \\
34\end{array}$ & $\begin{array}{l}0 \cdot 3 \\
8 \\
0 \cdot 5 \\
0 \cdot 5\end{array}$ & $\begin{array}{l}0 \cdot 14 \\
1 \cdot 2 \\
0 \cdot 2 \\
0 \cdot 26\end{array}$ \\
\hline $\begin{array}{l}\mathrm{J} \\
\mathbf{K} \\
\mathbf{N}\end{array}$ & $\begin{array}{l}\text { II } \cdot 4 \\
\text { II } \cdot 3 \\
\text { II } \cdot 3 \\
\text { III } 1 \\
\text { III } \cdot 3 \\
\text { III } \cdot 4 \\
\text { III } \cdot 5 \\
\text { IV } 2 \\
\text { II } \cdot 2 \\
\text { II } \cdot 1\end{array}$ & $\begin{array}{l}22 \\
27 \\
17 \\
28 \\
25 \\
20 \\
44 \\
22 \\
11 \\
25\end{array}$ & $\begin{array}{l}D 3 S 732, D 3 S 18 \\
D 3 S 732 \\
D 3 S 18 \\
D 3 S 18 \\
D 3 S 18 \\
D 3 S 18 \\
R A F 1 \\
R A F 1, D 3 S 18 \\
R A F 1 \\
D 3 S 18\end{array}$ & $\begin{array}{r}35 \\
29 \\
42 \\
27 \\
32 \\
39 \\
9 \\
35 \\
47 \\
32\end{array}$ & $\begin{array}{l}0 \cdot 5 \\
13 \\
2 \\
6 \\
2 \cdot 5 \\
2 \cdot 5 \\
10 \\
0 \cdot 06 \\
13 \\
1\end{array}$ & $\begin{array}{c}0.27 \\
5.8 \\
1.5 \\
2.3 \\
1.2 \\
1.6 \\
1.1 \\
0.03 \\
11.7 \\
0.5\end{array}$ \\
\hline
\end{tabular}

D3S18 interval as reported by Hosoe et al. ${ }^{8} \mathrm{It}$ should be noted that the genetic linkage results presented in this paper were calculated using different age dependent penetrance values than in the original papers, ${ }^{89}$ and that sex specific results are presented for the first time. We found significant sex specific differences in recombination fractions with VHL disease for $R A F 1$ and $D 3 S 18$, and DNA based prediction is likely to be more accurate in the offspring of affected males than of affected females. Although a higher recombination fraction in females was not reported in previous genetic linkage studies of VHL disease, ${ }^{8-10}$ the genetic map constructed by Hosoe et al from studies in $40 \mathrm{CEPH}$ families estimates the genetic distance between $R A F 1$ and $D 3 S 191$ to be $4.9 \mathrm{cM}$ in males and $10.7 \mathrm{cM}$ in females. Another finding of the combined study was the confirmation of the lack of evidence for locus heterogeneity which had been reported in the two previous individual studies. Interfamilial differences in predisposition to phaeochromocytoma are well recognised in VHL disease. In some families phaeochromocytoma is the most frequent complication but in others it is rare. The evidence of our individual and combined studies would suggest that this clinical heterogeneity results from allelic heterogeneity and not locus heterogeneity. Seizinger et $a l^{10} \mathrm{did}$ not find evidence of true locus heterogeneity in 28 families with VHL disease (although one family gave atypical results). Nevertheless, the possibility of locus heterogeneity in VHL disease with only a small number of unlinked families (as in adult polycystic kidney disease) cannot be completely excluded until even more families have been investigated.

We have shown that in families with suitable structure, linked DNA markers can be used to estimate the risk to unaffected family members. These results confirm those of Glenn et $a l^{13}$ who used RFLPs at five loci close to the VHL gene (RAF1, D3S18, D3S191, D3571, and D3S627), and found that $42 / 48(88 \%)$ subjects at risk for VHL disease were informative for presymptomatic diagnosis. Using RFLPs at three loci (RAF1, D3S732, and $D 3 S 18$ ) we were able to modify the risk for $70 \%$ of at risk subjects. It is clear that (in families with suitable structure) most subjects at risk for VHL disease will be informative for presymptomatic diagnosis using linked DNA markers. Although all the persons undergoing presymptomatic diagnosis were at $50 \%$ prior risk (that is, had an affected parent and were at $50 \%$ risk at birth), an age related risk can be calculated for each subject by using their current age and the known age dependent onset of VHL disease (table 1) in a Bayesian calculation. ${ }^{14} \mathrm{~A}$ combined age related and DNA based risk can then be calculated using similar methods. The final column in table 5 illustrates the utility of this approach. Subject III. 5 in family J has a predicted risk of $10 \%$ by RFLP analysis. However, at the age of 44 years the penetrance of VHL disease is 0.9 . Combining the age related risk with the DNA based risk results in a final risk of $1 \cdot 1 \%$. For many subjects undergoing presymptomatic 
diagnosis the age related risk was substantially less than $50 \%$ and this accounts for the finding that the majority of informative subjects (14/ 17) were predicted to be at low risk. Glenn et $a l^{13}$ found that 33 of 42 informative subjects were predicted to be at low risk on DNA analysis and all nine high risk subjects had subclinical evidence of VHL disease on detailed investigation.

The validity of DNA based prediction was established by the results of the combined study of 46 families. Presymptomatic diagnosis of VHL disease using closely linked DNA markers will improve the efficiency of screening programmes for at risk relatives by allowing resources to be concentrated on those subjects shown to be at high risk. Relatives found to be at low risk can be screened less frequently and stringently. However, although no evidence for locus heterogeneity has yet been found, it would be premature to discharge young relatives completely from further follow up on the basis of favourable DNA results alone. DNA based diagnosis is subject to a small error rate and in view of the potentially serious consequences of a false negative diagnosis, a detailed ophthalmological and radiological assessment is indicated in all subjects undergoing presymptomatic diagnosis by DNA markers. Glenn et al $^{13}$ reported that one out of 33 subjects predicted to be at low risk on DNA analysis was found to have a renal cell carcinoma on systemic screening.

As more informative closely linked DNA markers become available the proportion of uninformative cases will diminish. The isolation and characterisation of the VHL disease gene will increase the accuracy of presymptomatic diagnosis by allowing direct mutation analysis and would extend the availability of presymptomatic diagnosis to families whose structure is not suitable for linkage based risk prediction. However, there will continue to be a place for linked DNA marker based predictions in confirming the results of mutation analysis and in families with mutations that are not easily characterised.

We thank Action Research, the National Kidney Research Fund, and the Iris Fund for the Prevention of Blindness for financial support. We are grateful to the many colleagues who have provided us with access to families, to the patients and relatives who took part in this study, and to Dr U Rapp for the p627 probe.

1 Melmon KL, Rosen SW. Lindau's disease. Am $\mathcal{F}$ Med 1964;36:595-617.

2 Lamiell JM, Salazar FG, Hsia YE. Von Hippel-Lindau disease affecting 43 members of a single kindred. Medicine (Baltimore) 1989;68:1-29.

3 Maher ER, Yates JR, Harries R, et al. Clinical features and natural history of von Hippel-Lindau disease. $Q \mathcal{f} \mathrm{Med}$ 1990;77:1151-63.

4 Maher ER, Iselius L, Yates JRW, et al. Von Hippel-Lindau disease: a genetic study. $\mathcal{F}$ Med Genet 1991;28:443-7.

5 Maher ER, Yates JRW, Ferguson-Smith MA. Statistical analysis of the two stage mutation model in von HippelLindau disease, and in sporadic cerebellar haemangioblastoma and renal cell carcinoma. $f$ Med Genet 1990;27:311-4.

6 Moore AT, Maher ER, Rosen P, Gregor Z, Bird AC. Ophthalmological screening for von Hippel-Lindau disease. Eye 1991;5:723-8.

7 Seizinger BR, Rouleau GA, Ozelius LJ, et al. Von HippelLindau disease maps to the region of chromosome 3 associated with renal cell carcinoma. Nature 1988;332:268-9.

8 Hosoe S, Brauch H, Latif F, et al. Localization of the von Hippel-Lindau disease gene to a small region of chromosome 3. Genomics 1990;8:634-40.

9 Maher ER, Bentley E, Yates JRW, et al. Mapping of the von Hippel-Lindau disease locus to a small region of chromosome $3 p$ by genetic linkage analysis. Genomics 1991;10:957-60.

10 Seizinger BR, Smith DI, Filling-Katz MR, et al. Genetic flanking markers refine diagnostic criteria and provide flanking markers refine diagnostic criteria and provide insights into the genetics of Von Hippel Lin

11 Bonner T, O'Brien SJ, Nash WG, Rapp UR, Morton CC Leder $\mathrm{P}$. The human homologues of the raf (mil) oncogene are located on human chromosomes 3 and 4 . Science 1984;223:71-4.

12 Tory $K$, Latif F, Modi W, et al. A genetic map of 96 loci on the short arm of human chromosome 3. Genomics 1992;13:275-86.

13 Glenn GM, Linehan M, Hosoe S, et al. Screening for von Hippel-Lindau disease by DNA-polymorphism analysis. fAMA 1992;267:1226-31.

14 Young ID. Introduction to risk calculation in genetic counselling. Oxford: Oxford University Press, 1991. 